\title{
A Proposed Systematic Framework for Applying Hoshin Kanri Strategic Planning Methodology in Educational Institutions
}

\author{
Hanaa Ouda Khadri Ahmed \\ Faculty of Education, Ain Shams University
}

doi: 10.19044/esj.2016.v12n16p158 URL:http://dx.doi.org/10.19044/esj.2016.v12n16p158

\begin{abstract}
Hoshin Kanri is a methodology that was developed in Japan in the late 1960s. Now, it has become an essential component in numerous institutions that are implementing new management systems and concepts such as Balanced Scorecard (BSC), TQM, and Lean Management or Six Sigma. Hoshin Kanri is a management method used for reinforcing strategic work. In spite of a number of Hoshin Kanri success stories in many sectors and a variety of institutions, little research attention has been given to the implementation of Hoshin Kanri methodology in educational institutions. This research supports an increased focus on Hoshin Kanri methodology in Strategic Planning for educational institutions. The main aim of this paper is to propose a systematic framework for applying Hoshin Kanri strategic planning methodology in educational institutions. In achieving this aim, the meaning and origins of Hoshin Kanri were defined, the foundations of Hoshin Kanri planning methodology were analyzed, the factors influencing the implementation of Hoshin Kanri planning in educational institutions were discussed, and a structured process for implementing Hoshin Kanri planning in educational institutions was developed.
\end{abstract}

Keywords: Hoshin Kanri, Policy deployment, PDCA cycle, Catch ball, Total Quality Management

\section{Introduction}

Yoji Akao (1991) stated that Hoshin kanri is a planning, implementation, and review framework for systematic planned change. The planning perspective focuses on strategy preparation; implementation includes activities which give precedence to, integrate, and that coordinate institutional actions; and the review framework focuses on activities which manages and controls actions through a combination of daily process control and repeated review. However, the application of total quality management 
(TQM) is what makes Hoshin Kanri unlike other strategy formulation and implementation methodologies. TQM is of a particular type where the plando-check-act (PDCA) cycle is applied at all levels and to all processes. This is combined with a full employment of quality tools to collect information, to detect issues, to classify critical actions, and to carry out solutions. The purpose of Hoshin Kanri is to build actions into the daily management that is consistent with the achievement of a few vital strategic priorities within a certain year (Witcher \& Butterworth, 1997).

\section{Strategy Implementation}

There are two clusters of strategy implementation. The first one is effective immediately after the decision making process. They include personnel, budgeting, or mergers and coalitions. On the other hand, the second one is successful only with an institution-wide effort such as Hoshin Kanri which is favored by the Japanese. This difference is a manifestation of two traditions in strategic management. One is a market-based perspective, while the other is a resource-based perspective of strategy. Michael Porter, the most distinguished scholar of the last three decades, and his ideas greatly focus on the external environment as an influential factor in the success of the strategy. Thus, the direction of influence is outside-in as shown in Figure 1 below (Witcher, 2014).

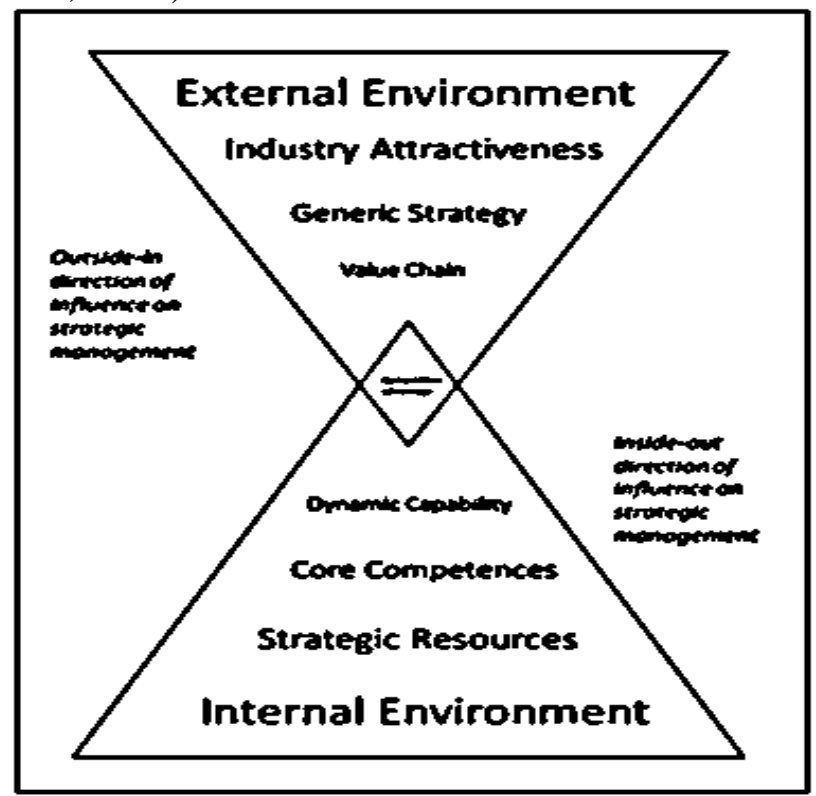

Figure 1. Outside-in and inside-out influences on strategy

(Source: Witcher \& Chau, 2012)

There are two strands of thinking in strategic management. The first strand of thinking in strategic management is centered on the idea of starting 
with the external environment. In addition, it also involves the use of a value chain to organize and direct the institutional activities to sustain the strategy. The second strand of thinking in strategic management is centered on the internal environment. Therefore, this is an inside-out approach to strategy thinking which considers strategic resources as non-economic resources. Nevertheless, they are institution-specific, which makes them problematic for competitors to understand and compete with. So the stress is on the internal environment instead of the external environment. Also, the direction of influence in formulating strategy is inside-out. However, Hoshin Kanri is generally perceived by strategists as a system for operations. Specifically, there is an institutional yearly review and it is of necessity that top management should manage the strategic management process to PDCA principles (Witcher, 2014).

\section{Problems with Strategic Planning}

The predominant methods of strategic planning and strategic implementation were marked with problems. Several strategies are unsuccessful to deliver for many reasons. As stated by Zairi \& Alan (2014), these reasons amongst others include:

- Goals are not communicated well- people working without clear direction.

- Changing the goal - numerous interruptions and modifications in direction.

- Interest in pet projects - favorite short-term goals due to the difficulty of long-term competitiveness.

- Cost is the essential driving force for results without regard to actual improvement opportunities.

- Goals created in isolation from the process.

- Voice of customer not actually captured.

- Achievements are not maintainable.

Consequently, one of the fundamental astounding phenomenon of Japan's success in controlling international markets for a long time is their approach to strategic planning. Hoshin Kanri planning has well-benefited Japanese institutions tremendously. Also, it has evidence to be a substantially disciplined, systematic, and has an integrated approach for putting strategies into operation. This was the situation at a time when there has been much criticism of the Western approaches to strategic formulation and implementation. Hoshin Kanri planning has been transferred from Japan to the US (King, 1989; Babich, 1996; Colletti, 1995). The acceptance of Hoshin Kanri planning in the West occurs as a result of adopting institution's Total Quality Management. Therefore, this is considered as an 'implied' consideration that Japanese institutions make. Also, they have continuously 
based their approach to doing business on the adoption of quality systems and techniques.

Hoshin Kanri is a strategic management method basically developed in Japan. Although, Hoshin Kanri is extensively adopted in Japanese leading companies such as Hewlett Packard, NEC Japan, Xerox, and Procter and Gamble (Akao, 1991), it has less extended to Western and Arab institutions in general and educational institutions in particular. There is an increasing potential of adopting Hoshin Kanri in institutions as a methodology. In addition, it is comprehensive in nature, i.e., it supposes the involvement of all employees and functions in an institution, and integrates strategies into daily operations (Kondo, 1998; Marksberry, 2011; Nicholas, 2014). In addition, it provides a substitute to overcome the generic problems of strategic management, in that it networks managers with employees by a systematic deployment process via vertical and horizontal communication. Here, the goals developed by the management were deployed and all efforts lines up with the vision and targets (Akao, 1991). Therefore, Hoshin Kanri presented a structured method of deployment, communication, and implementation.

Interpreting institution strategy into operational strategy has been a foremost center of attention of operations management for numerous decades. Skinner (1969) stated that findings about operational dimensions as the left behind link in institution strategy was a milestone. If an institution is not aware of this link, it may finish up with noncompetitive system. Furthermore, he indicated that the cause-and-effect factors which determines the link between strategy and production operations is indefinable.

Leonard \& McAdam (2002) declared that management pays attention to hand over the implementation of strategy to operational levels devoid of presenting the general strategic concept. However, this concept results to defects in translating strategy into objectives and deliverable attainable activities. Hoshin Kanri, as a strategic management tool, concentrates on the vision of the institution. In addition, it calls attention to the importance of the distribution of strategies down to operational initiatives.

\section{Why Hoshin Kanri?}

The essence of essential problems, particularly in an ever changing dynamic and complex environment, necessitates an essential change on how strategic planning process is conducted. The focus of strategic planning process must change from determining the solution for problems which are believed to exist, to defining a responsive process to the wicked characteristics of the assumed problems. This process is dynamic and changes continuously as long as additional learning happens. Furthermore, this process is also comprehensive, repetitive, cross functional, cross- 
hierarchical, and self-correcting (Gilmore \& Camillus, 1996). Mulligan et al. (1996) stated that:

"A major strength of Hoshin is its added dimension of adaptability that arises from the constant application of Deming's PDCA methodology."

Consequently, Hoshin Kanri is concerned with the following four primary tasks (Witcher \& Butterworth, 1999):

1. Providing a concentration on the direction of the institution by developing a few strategic priorities annually;

2. Adjusting the strategic priorities with institutional plans and programs;

3. Integrating the strategic priorities with day-to-day management;

4. Offering a systematized review on the development of the strategic priorities.

Hoshin Kanri aims to manage the direction of the institution by directing change within an institution. Hoshin Kanri includes tools for continuous improvement, breakthroughs, and implementation. The basic idea of Hoshin Kanri planning is that it involves the whole institution in the strategic planning process, both top-down and bottom-up. In addition, it ensures that the direction, goals, and objectives of the institution are logically created, clearly defined, well communicated, monitored, and adapted based on a feedback system (King, 1989). Hoshin Kanri defines specific yearly target policies obtained from the long and medium term policies that encompass the long term visions of the institution. It achieves targets via action plans that intend to develop the control system. Thus, these action plans are deployed for their targets and policies (Akao, 1991).

Many leading companies have used Hoshin Kanri, which offers an alternative method, to vanquish the normal problems associated with strategic management. This is possible because it links managers and employees by a methodical deployment process through vertical and horizontal communication. Here, the goals developed by the management are deployed and all efforts are aligned to the same vision and goal (Akao, 1991).

\section{What is Different about Hoshin Kanri?}

Hoshin Kanri involves both directions in the institution: Top-down and bottom-up. Top to down direction is concerned with Vision and long term plans. Also, lower levels are providing their feedback in order to improve the process by their creative ideas. This interaction between the various levels of institutions and team works is presented in figure 2. 


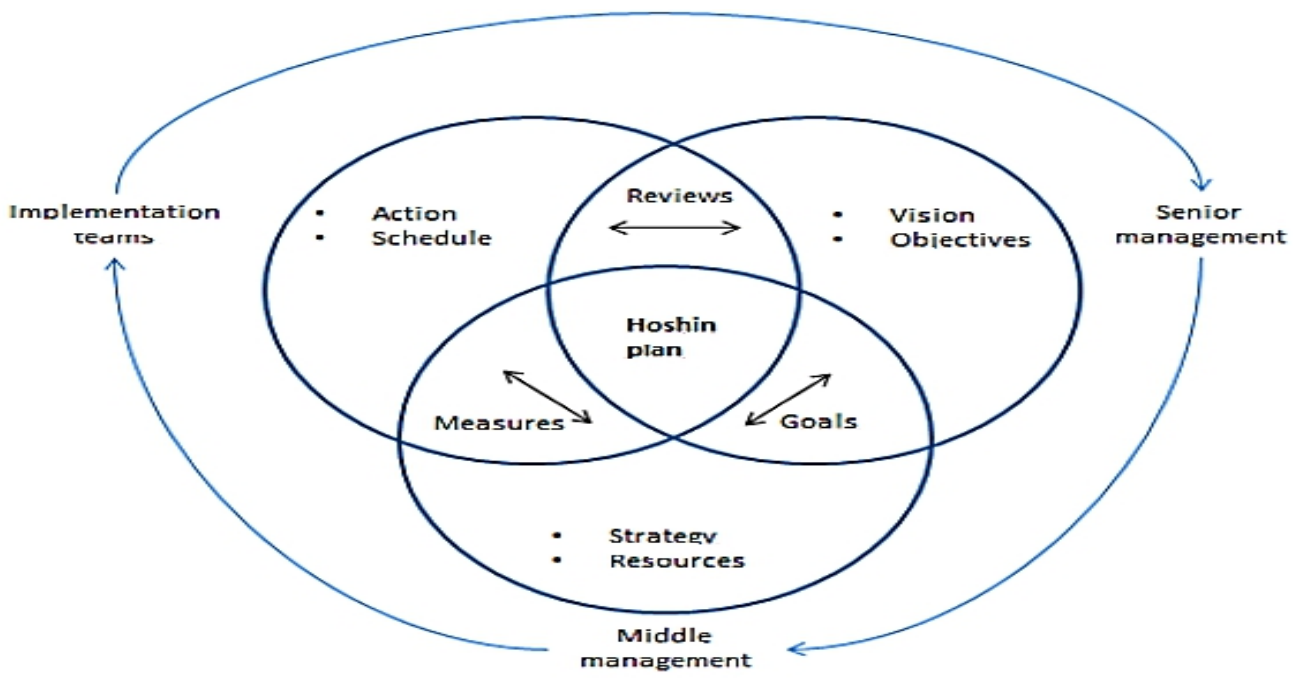

Figure 2. Hoshin model

(Source: Leppänen, 2014).

Hoshin Kanri management has its unique features which greatly differentiates it from the typical management systems. Hoshin Kanri management aims at making the whole institution to work in the same direction through vertical and horizontal alignment of the objectives, targets, and means. In addition, Hoshin Kanri transfers the focus on the management from the results to the processes. That is to say from output to input. Therefore, this actually leads to the development of the processes which is producing better results. Figure 3 indicates the difference between Hoshin Kanri and institution with conflicting targets.

\section{Hoshin policy for the organisation}

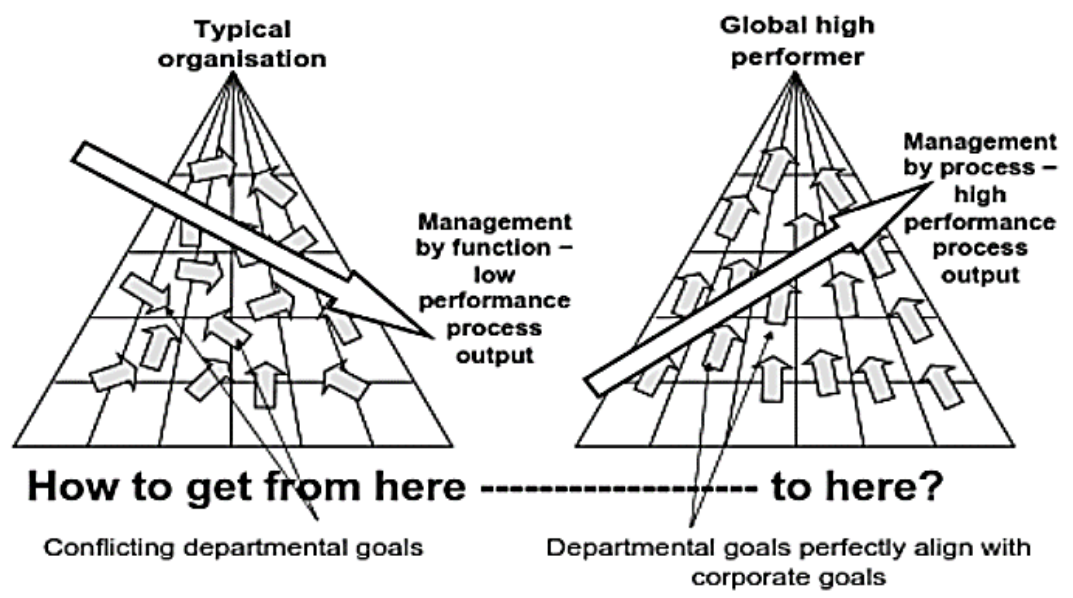

Figure 3. Comparison between the extremes of management style

(Source: Hutchins, 2008). 
Tennant \& Roberts (2000) indicates that one of the fundamental features of Hoshin Kanri is the focus of Hoshin breakthrough strategy management. Thus, this management strategy involves the improvement of the whole multifunctional processes, rather than process improvements inside the divided levels of the institution (Hutchins, 2008). Figure 4 presents the comparison of the strategy management systems.

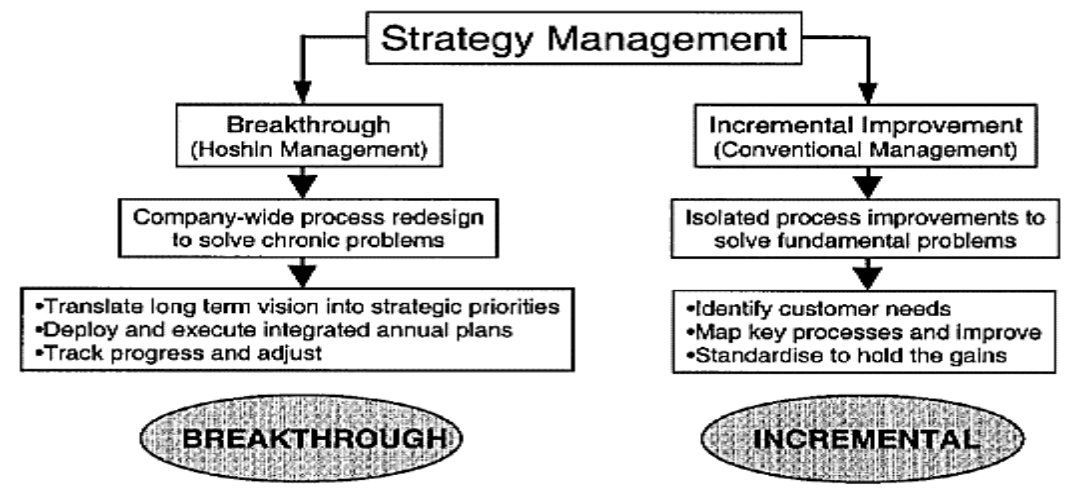

Figure 4. Breakthrough and incremental strategy management

(Source: Tennant \& Roberts, 2000)

Strategic management involves the integration of an institution's vision, goals, policies, and tactics into a cohesive unified whole. After the vision and foremost policies have been determined, the tools for implementation must be identified. Therefore, these tools are required in managing the institution. Also, it is very important for institutions to decide on the applicable and fitting tools, which will cohesively interconnect with the strategic and operational initiatives during the implementation process. This study is concerned with such strategic management tool- Hoshin Kanri to structure and implement strategies.

Based on the previous discussion, it is clear that for an educational institution to stay competitive, it is fundamental to develop distinctive resources or competencies to translate institutions goals into operational strategy and targets. It is this interpretation into suitable and purposeful metrics and targets at each level of the institution, that is to say, the means used by an institution to manage and develop its resources, which decides its competitive advantage. Nevertheless, despite its importance, a structured and systematically approach especially at the operations level was missing.

Literature in general indicates that there is a gap regarding how institutions manage strategy. Till date, they have failed to identify and develop deep knowledge of Hoshin Kanri as an important means of filling this gap. Hoshin Kanri methodology presents significant features on how strategy can be managed in daily operations. Therefore, the current study 
aims at promoting a proposed systematic framework for applying Hoshin Kanri strategic planning methodology in educational institutions.

\section{Statement of the Research Problem}

In the light of what has been mentioned, this paper seeks to propose a systematic framework for applying Hoshin Kanri strategic planning methodology in educational institutions. In achieving the objective, this study will answer some questions.

Therefore, the main research question in this study is:

What is the systematic framework for applying Hoshin Kanri strategic planning methodology in educational institutions? Furthermore, this question is broken down as follows:-

1. What are the definitions of Hoshin Kanri and the related concepts?

2. What are the origins of and historical context of Hoshin Kanri?

3. What are the foundations of Hoshin Kanri planning methodology?

4. What is the difference between Hoshin Kanri planning process and any other strategic planning process?

5. What are the factors influencing the implementation of Hoshin Kanri planning in educational institutions?

6. What is the structured process for implementing Hoshin Kanri planning in educational institutions?

\section{Objectives of the Study}

The main objectives of this study are to:

1. Define the concept of Hoshin Kanri planning and the related concepts.

2. Track the origins of and historical context of which Hoshin Kanri was developed.

3. Analyze the foundations of Hoshin Kanri planning methodology.

4. Identify the difference between Hoshin Kanri planning process and any other strategic planning process.

5. Discuss the factors influencing the implementation of Hoshin Kanri planning in educational institutions

6. Develop a structured process for implementing Hoshin Kanri planning in educational institutions.

\section{Significance of the Study}

1. This study may contribute to the field of strategic planning in education. This is because it provides a systematic framework for applying Hoshin Kanri strategic planning methodology in educational institutions.

2. The strategists may benefit from this study by virtue of applying Hoshin Kanri strategic planning methodology. 
3. This study may increase the understanding of how Hoshin Kanri strategic planning methodology can be initiated in educational institutions.

\section{Research Method}

The paper is based on literature reviews of theoretical and practical researches on Hoshin Kanri methodology and strategic management. Thus, the structured process for implementing Hoshin Kanri planning in educational institutions was developed from the Hoshin Kanri literature. This was, however, integrated with the knowledge attained by the researcher through a Face to face workshop. Consequently, this workshop is divided into interactive sessions conducted under close guidance through an interview with 45 persons responsible for the strategic planning in some of the Egyptian public and private universities. The interview was held during the lectures conducted by the researcher as a part of the teaching practices of "strategic planning in educational institutions" course. However, this is one of the courses in Professional Diploma in Quality and Accreditation Management Systems in the Educational Institutions at Ain Shams University.

\section{The Definitions of Hoshin Kanri and the Related Concepts Hoshin Kanri}

In this study, the accurate meaning of 'Hoshin Kanri' is perplexed in the linguistic vagueness as understood in its translation from Japanese. The common translation of Hoshin Kanri includes Hoshin as 'policy' or 'target and means', and Kanri as 'planning' or 'management or control'. The word Hoshin is made up of two Chinese characters: ho and shin. ho means method or form, while shin means shiny needle or compass. Kanri means management or control. The two words when put together mean a 'methodology for strategic direction setting'. The most literal translation is policy management. Consequently, a collection of different terms have been adopted within a Western context. Such terms embraces policy deployment, policy control, management by policy, managing for results, and Hoshin planning (Akao, 1991; Jolayemi, 2008; King, 1989; Shiba, 1993). As a result of this multiplication of terms, the term "Hoshin Kanri" will be adopted in this paper.

Furthermore, different authors have presented a variety of definitions or interpretations to Hoshin Kanri (Nicholas, 2014; Kondo, 1998; Marksberry, 2011; Lee \& Dale, 1998; Jolayemi, 2008). The meaning of Hoshin is shining metal, pointing direction or compass, while Kanri means management or control (daily) (Jolayemi, 2008). Thus, the two words put together communicate the essential idea of the methodology. 

follows:

King (1989) in Witcher (2014, p. 74) describes Hoshin Kanri as

"Hoshin [kanri] helps to control the direction of the institution by orchestrating change within an institution. This system includes tools for continuous improvement, breakthroughs, and implementation. The key to Hoshin [Kanri] is that it brings the total institution into the strategic planning process, both top-down and bottom-up. It ensures the direction, goals, and objectives of the institution are rationally developed, well defined, clearly communicated, monitored, and adapted based on system feedback." Akao defined Hoshin Kanri as:

"All organization activities for systematically accomplishing the long and mid-term goals, as well as yearly business targets which are established as the means to achieve business goals. In many cases, it is used for yearly targets." (Akao, 1991, p.47)

Total Quality Engineering (1997) defines Hoshin Kanri as:

"A system of forms and rules that encourage employees to analyze situations, create plans for improvement, conduct performance checks, and take appropriate actions."

At the same time, Integrated Quality Dynamics (1997) defined Hoshin as:

"A one-year plan for achieving objectives developed in conjunction with management's choice of specific targets and means in quality, cost, delivery, and morale".

or in "catch-phrase" form

Hoshin = target + means

Akao, also debates that Hoshin Kanri's exceptional intent is to "integrate an entire organization's daily activities with its long term goals." (Akao, 1991, p. xiii)

It can be concluded that Akao suggests a management process which includes all the activities that relate to the strategic management process. Thus, his definition is in agreement with the translation of Hoshin Kanri as a 'method for strategic direction setting'.

Witcher \& Butterworth (1997) say:

"What makes Hoshin Kanri different from other strategy formulation and implementation methodologies is the application of total quality management."

Watson (1991) simply says:

"Perhaps, the most accurate term for Hoshin Kanri would be target-means deployment."

However, I think Hoshin Kanri is a process-oriented methodology and an organizing system for structuring and implementing strategies that 
define precisely the direction, all through the whole institution, via integrating the entire institution's daily activities with its strategic goals.

\section{Policy Deployment}

The term "policy deployment" is a popular term generally used interchangeably with Hoshin Kanri. The term 'policy' is used to include both 'target and means'. A 'target' is a quantifiable objective stemmed from policy, while 'means' explains the exact steps for the accomplishment of the target. Thus, this is in explicit contrast to the limited understanding of policy in the West which refers to a top down directive method. On the other hand, 'target' refers to numerical, functional, and operational objectives. Deployment refers to a process of devolving the targets and means all through the organization (Akao, 1991).

Rank Xerox (1992) defines policy deployment as follows:

"A key by which Rank Xerox can articulate and communicate the Vision, Mission, Goals, and Vital Few Programs to all employees. It provides the answers to the two questions: "What do we need to do?" and "How are we going to do it?"

\section{Hoshin Kanri: Its Origins and Historical Context}

Hoshin Kanri appeared in the 1950's. The origin is unspecified, but it is mentioned that the idea of the methodology initiated a course on quality control sponsored by the Japan Association of Science and Technology (Tennant \& Roberts, 2001a). Therefore, the basis of Hoshin Kanri is a combination of Edward Deming's lectures on the PDCA cycle. It also has to do with the causes of variation and process control jointly with Peter Drucker's “Management by Objectives” philosophy (Drucker, 1954). The next turning point was in 1962 when the Bridgestone Tire Institution developed Hoshin Kanri as a management system integrated with their Total Quality Control (TQC) methodology (later TQM) (Akao, 1991). The next phase was when Akao and Mizuno coached Yokagawa Hewlett-Packard on a prize winning status in the 1970's. Hence, through that, the approach was diffused to America (Watson, 2005). Since then, the relation has been deeprooted between Total Quality Management (TQM) and Hoshin Kanri. Witcher \& Butterworth (1997) stated that this relation defines the distinctiveness of the approach as Hoshin Kanri represents the application of TQM in strategy. Afterwards, "Hoshin Kanri presented an organizational architecture and transparency which is imperative if strategy and daily management are to combine in their use of TQM" (Witcher \& Butterworth, 1999, p.324).

One of the great successes of Japanese corporations during the 1980s is that they witnessed the increase of new institutions that wanted to adopt 
total quality. One of these institutions was Growth Opportunity Alliance of Greater Lawrence, “GOAL/QPC”. However, it is a nonprofit educational institute, founded in 1978 as a community-based group to advance jobs. It advocated Hoshin Kanri (Cole, 1998). In 1988, it formed a members' research team to advance Hoshin Planning/Management by Policy. Its members include Dow Chemical, Procter \& Gamble, Hewlett Packard, and IBM. Furthermore, they developed the first English language report about Hoshin Kanri (GOAL/QPC, 1989). In the same year, Bob King, a GOAL/QPC executive, published his text which was based on a visit to Japan by GOAL/QPC delegates the previous year (King, 1989).

\section{Foundations of Hoshin Kanri Planning Methodology}

Hoshin Kanri was created in Japan and emerged from the principle of continuous improvement of tranquility in total quality management. It is a system that concentrates on quality control and continuous improvement activities (Akao, 1999, p. 49). Concurrently, Hoshin Kanri measures the level of reaching the goals defined by improvements (Akao, 1999, p. 43).

Hoshin Kanri also conveys institution policy to every person in the institution. Hoshin's foremost focus is to consternate efforts on the fundamental issues essential for achieving success. Japanese Deming Prize winners credit Hoshin to be an outstanding key contributor to the success of their business. Advanced US institutions, such as Xerox and Hewlett Packard, have also adopted Hoshin as their strategic planning process. Hoshin meets the intent of the Malcolm Baldrige National Quality Award criteria for Planning, but with different approach. This approach entails that Hoshin is a system of procedures and instructions that support employees to investigate and examine environments, develop plans for improvement, conduct performance checks, and take suitable actions (Akao, 1999).

\section{Hoshin Kanri as a Cyclical Framework for Strategy Management}

Hoshin Kanri is a cyclical framework for strategy management. It focuses on four fundamental tasks and the cycle is a yearly one as shown in figure 5. Firstly, it concentrates an institution's interest on corporate direction by setting a few vital strategic priorities every year. Secondly, it aligns these strategic priorities with institution plans and objectives. Thirdly, it integrates them with daily management. Lastly, it provides a structured review of their progress. Therefore, this way involves Focus - Alignment Integration - Review (FAIR) (Witcher \& Butterworth, 1999).

Hoshin Kanri is composed of two dissimilar levels. The first level is strategic planning (Hoshin), while the second level is day-to-day management (Kanri). Therefore, these two levels need to be carried out before the completion of the system. That is to say that Hoshin Kanri is not 
just a process for the senior management to build visions and long term goals and objectives, but it is also a process for middle management and implementation groups to apply PDCA- cycle to the daily life of the institution (Leppänen, 2014).

\section{The Relationship between Hoshin Kanri and Total Quality Management (TQM)} The Quality Deployment Process

Hoshin Kanri is a quality management tool. It has its origins in comprehensive quality thinking. To understand the power of Hoshin, the foundations and constraints of TQM must be understood.

Hoshin Kanri planning is the mandatory prerequisite for processes to be performed well and for goals to be successfully achieved. Hoshin Kanri planning is the tool by which quality effort is flown down all through the institution. Hoshin Kanri planning is a top-down approach. Therefore, it is considered to be the responsibility of senior managers. Process improvement and measurement is seen as a horizontal effort, while quality deployment is regarded as a vertical approach. As shown in Figure 5, quality improvement is a continuous effort. Therefore, it is not limited and finite. Nevertheless, the institution has to measure and quantify its quality effects against specified targets (Akao, 1990). Hoshin Kanri planning is not simply a communication process. Hence, it is a dynamic process where performance measurement is regarded as a fundamental part and where goals are translated into clear actions all through the various activities of the institution. Quality function deployment is the horizontal process which guarantees that performance will follow from the goal of the communication effort.

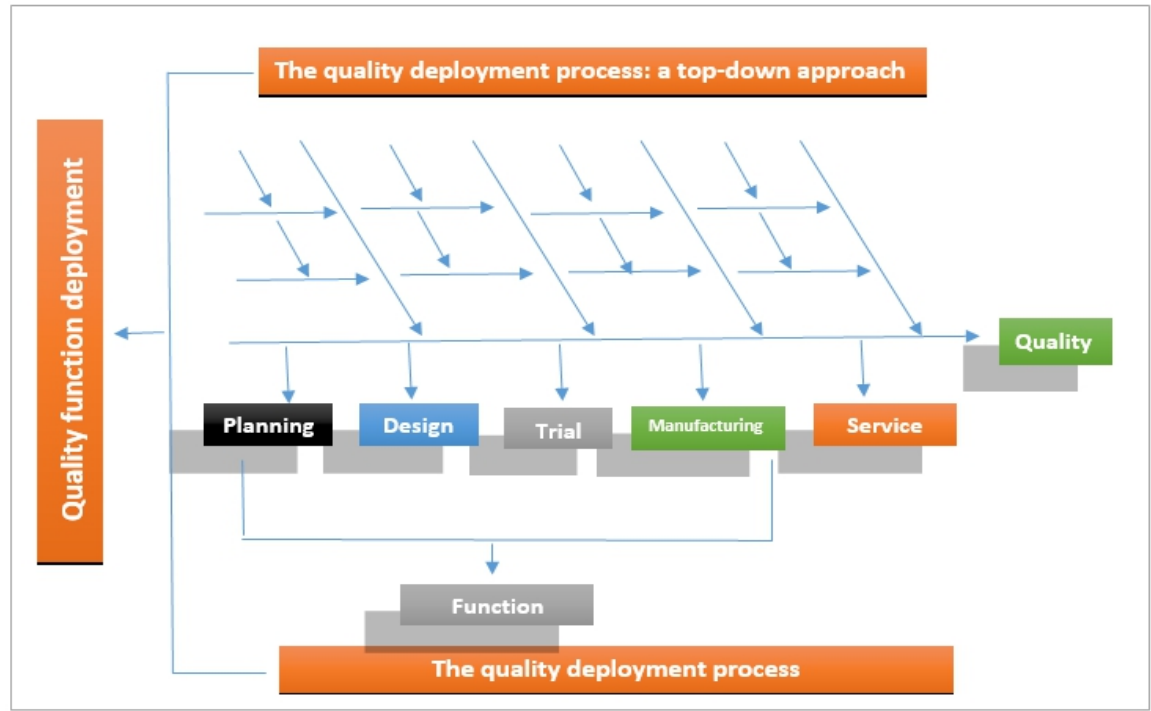

Figure 5. The quality deployment process (Source: Akao, 1990) 


\section{Hoshin Kanri through the PDCA Cycle}

The Deming cycle of Plan-Do-Check-Act (PDCA) is applied in the context of Hoshin (i.e. strategically continuous improvement). As illustrated in figure 6 (American Supplier Institute, 1989), the PDCA drives the strategy and guarantees that the goals are accomplished. In addition, all the necessary adjustments will be made as and whenever it is necessary. Also, it is done when learning process takes place continuously. Hoshin Kanri is also about an intentional and planned top-down positioning of yearly 'vital few' programs. It is employed since too many programs can result to distraction. Additionally, these programs should be crystal clear and translatable for everybody. Thus, persons should be able to find the means of implementing them. Strategy is deployed as strategic intent, and corporate strategy is expressed in some limited statements. Furthermore, there are no detailed formulation of procedures, activities, and objectives for others to accomplish. This approach is based on constant improvement and advanced change. In addition, it is grounded on what is reasonable and open to discussion (Witcher \& Butterworth, 1999).

\section{Focus - strategic priorities}

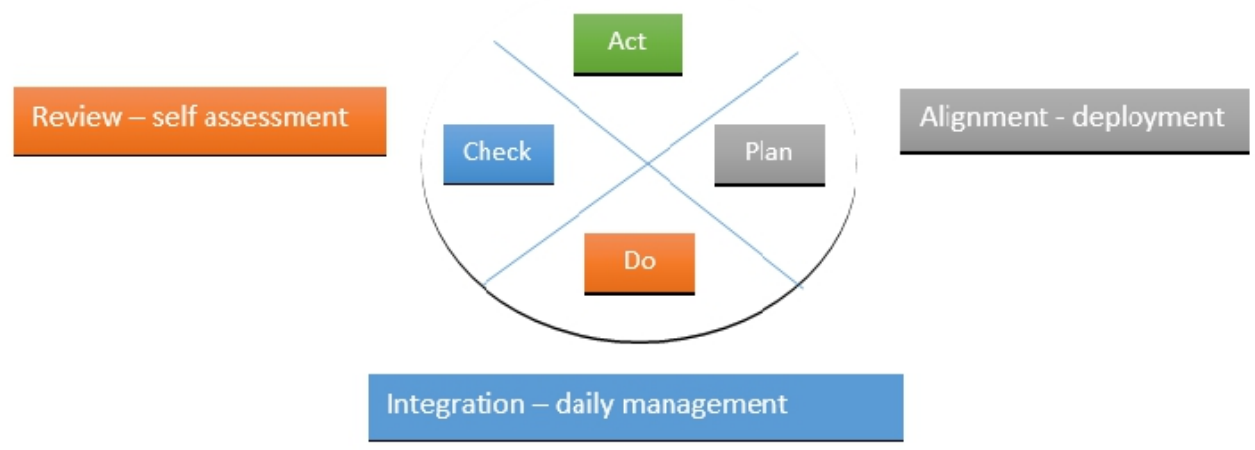

Figure 6. Hoshin Kanri planning through the PDCA Cycle

(Source: Witcher \& Butterworth, 1999)

\section{The "FAIR" Model of Hoshin Kanri}

FAIR is an annual cycle which commences when management starts to review the previous year's performances and develops the strategic target for the next year. Therefore, this is expressed as the 'vital few targets'. After the 'plan' phase, the vital few targets are aligned with annual plans and implemented by the 'catchball process' through the business units. Then, the cycle turns to the 'do' phase which focus on the integration of the vital few objectives into daily management. As a result, the plans are implemented where the PDCA cycle is performed continually for taking corrective 
actions, process improvement, and standardization. The 'control' phase is a review of the annual performance. Data from a completed cycle are fed back into the act phase, so that the cycle starts over (Witcher \& Butterworth, 1999).

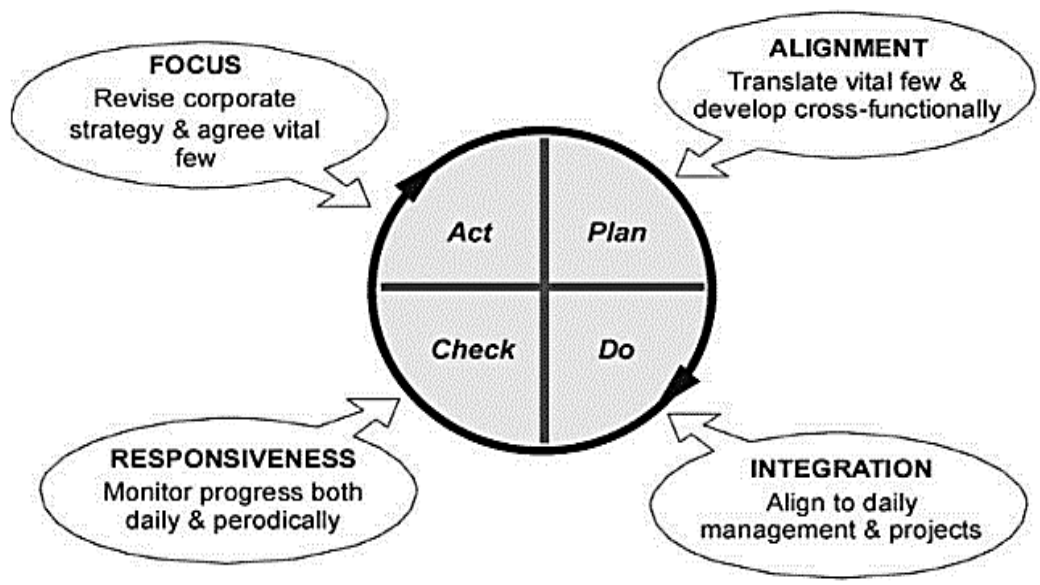

Figure 7. The "FAIR" model of Hoshin Kanri

(Source: Tennant \& Roberts, 2001b)

The act stage of the cycle is that which produces institutional FOCUS.

The plan stage of the cycle produces institutional ALIGNMENT.

The do stage of the cycle produces institutional INTEGRATION.

The check stage of the cycle produces institution wide REVIEW.

(Witcher \& Butterworth, 1999)

\section{The Relationship between Hoshin Kanri and Strategic Management}

Hoshin Kanri is considered as a strategic mechanism for setting direction, and moving the institution towards the selected direction. Hoshin Kanri is considered to be an advanced modern derivative of strategic management. This is because strategic planning has been practiced by 'Western' institutions since the 1960's (Ansoff, 1968). When a comparison has been made between Japanese and Western forms of strategic management, on one hand, it is found that the essential difference between Japanese and Western forms of strategic management is the extent of details in the senior management planning process. Hence, this is with the Japanese management adopting the technique of setting 'Strategic Intent' instead of carrying out a process of strategic planning. On the other hand, there are well-defined similarities which are needed to adopt a new management paradigm which is about setting the direction. Thus, it debates the means with the workforce. Subsequently, where all the strategic planners fail, the 
next step is to put a reasonable and practical system for managing implementation.

Recent works in Strategic Management provide little in the way of guidance for implementation. Perhaps, the reason behind that is the assumption adopted among all strategy thinkers. This assumption states that if the strategy is good, it would implement itself, or it can be implemented through existent means. Possibly they think that implementation is case specific, so a generic model cannot be created. Whatsoever the justification, not taking this issue into consideration will persist to constrain the impact of strategic thinking. Davidson (1995) expresses the differences between the old paradigm of 'Command and Control' and the new paradigm of 'Managing Change' in which a great attention given to the role of the 'new manager'. In Davidson's thinking, Change Management has its foundation in leadership, common purpose, and the values and the role of the manager as a facilitator and mentor.

\section{The Relationship between Hoshin Kanri and Cross Functional and Daily Management}

Cross functional management can be defined as control activities that consist of planning for components like Quality, Cost, Delivery, and Employee (QCDE). Daily management or departmental/functional management can be defined as the whole activities that each department must carry out daily. In addition, they are necessary to accomplish their business goals. Akao defines Hoshin Kanri “as all organizational activities for systematically accomplishing the long and mid-term goals as well as yearly business targets, which are established as the means to achieve business goals” (Akao,1991, p. 47). In Hoshin Kanri, management of targets that relates primarily to the functions of Quality, Cost, Delivery, and Employees require an approach that can cross institutional boundaries. Consequently, daily management means that the fundamentals of total quality management of all the activities of an organization must be performed daily.

\section{The Relationship between Hoshin Kanri and the Balanced Scorecard}

There is a clear link between the balanced scorecard as a strategic management system and Hoshin Kanri. Schneiderman has created the prototype scorecard in 1987 when he was the Vice President of Quality and Productivity at Analog Devices Incorporated (Schneiderman, 1999, p. 7). Analog was mentioned in the article of Kaplan \& Norton (1992). Hoshin Kanri was used to implement the scorecard at Analog Devices Incorporated. The balanced scorecard's four perspectives are similar to the cross-functional management of QCDE objectives: quality parallels to the customer 
perspective; the cost, delivery, and employee objectives parallel to the financial, internal business process; and the learning and growth perspectives. While the balanced scorecard is focused on choosing and monitoring the correct measures to direct change, Hoshin Kanri is mainly concerned with the capability of the institutional processes that provide value to the customer. Furthermore, while the balanced scorecard is valuable on what should be done, there is no much to say, at the same time, about how it should be done (Witcher, 2014)

\section{The Relationship between Hoshin Kanri and Performance Management}

May be the best description of Hoshin Kanri planning is the process which seeks to achieve agreement and clearly answers the questions: "what to do" and "how to perform". Performance measurement, on the other hand, measures motion, action, and significant addition. The two activities of Hoshin Kanri and performance measurement are (Zairi \& Alan, 2014):-

1. Process Management: It is a senior management accountability which has the authority of making the right decisions, creating the appropriate objectives, and communicating with them at all levels.

2. Performance Measurement: Quality improvements happen through team efforts and a multi-functional approach. Therefore, performance measurement became the responsibility of the members of staff who have the critical task of performing the essential improvements.

Therefore, Hoshin Kanri and performance measurement have to concentrate not merely on defects and negative gaps, but also on quality and the preservation of competitive advantages. Consequently, measures are of significant importance at two levels (Zairi \& Alan, 2014):-

1. Strategic Benchmarking: It is used to create strategic objectives and critical success factors (CSFs) through a systematic understanding of customer requirements and process capability.

2. Operational Benchmarking: It is used to raise process capability at all levels through formation of new practices and methods learned from leading institutions. 


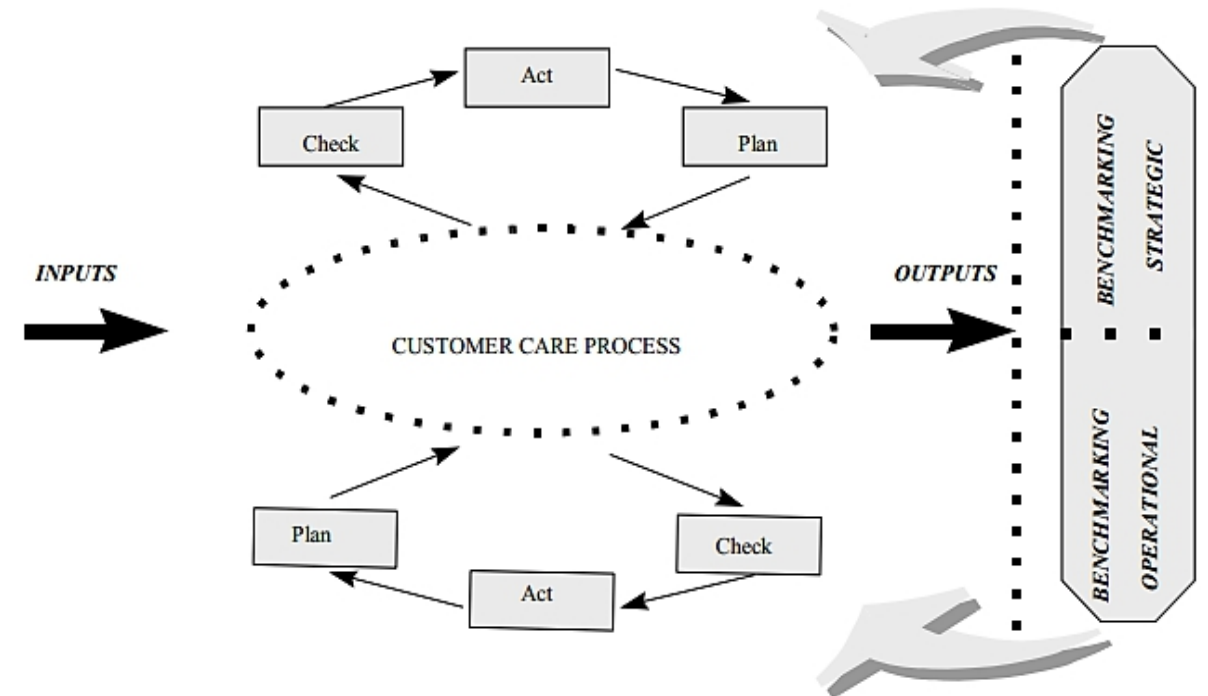

Figure 8. Integrating process management and performance measurement

(Source: Zairi \& Alan, 2014)

\section{The Principles of Hoshin Kanri}

The principles of Hoshin Kanri can be summarized as follows (Lee

\& Dale, 1998):

1. Concentration on processes, not results;

2. Based on day-to-day control;

3. Goals are contingent on customer needs;

4. Profound analysis of previous stage;

5. Top-down and bottom-up planning;

6. Catchball between different levels of institution;

7. Objectives aligned all over the institution to accomplish common goals;

8. Each and every one in the institution is responsible for the process of bringing about the results;

9. Emphasis on a few number of advanced items;

10. Prevalent understanding of TQM and the PDCA cycle;

11. Means deployed with targets;

12. Recurring review mechanism, emphasis on corrective action;

13. Active, flexible, and endlessly improvement. 


\section{Hoshin Kanri Process}

\section{The Critical Elements of Hoshin Kanri Processes}

Jolyaemi (2008) and Nicholas (2014) pinpointed the critical elements of Hoshin Kanri processes. These critical elements are: PDCA, Vision, strategy, long and medium-term goals, Cascade objectives, Catch ball, Means/ends and targets, and Objectives connected to every day work. Generally, Hoshin process entails the PDCA methodology.

\section{PDCA}

Hoshin Kanri has been described as "simply PDCA applied to the planning and execution of a few critical (strategic) institutional objectives" (King, 1989, in Witcher, 2014, p. 73). However, PDCA is the Deming's $\mathrm{P}(\mathrm{lan}), \mathrm{D}(\mathrm{o}), \mathrm{C}(\mathrm{heck})$, and $\mathrm{A}(\mathrm{ct})$ problem solving process (Jolayemi, 2008; Sobek \& Smalley, 2008; Witcher, 2014).

\section{Vision, Strategy, Long and Medium-Term Goals}

In Hoshin Kanri yearly, strategic objectives are derived from the vision and long term strategy into some strategic objectives (3 - 5) that should be attained throughout the year (Nicholas, 2014; Witcher, 2014).

\section{Cascade Objectives}

Based on the few strategic objectives, key functions are determined and are involved in the analysis, planning, and execution processes. The objectives and plans are cascaded to all levels in the institution.

\section{Catch Ball}

The catchball process is at the heart of Hoshin Kanri, which is the main process for the aligning and integrating of strategies. Catch ball refers to the two-way, top-down, and bottom-up process by which objectives and plans are distributed and shared out in the institution. Thus, the objectives, plans, and activities at every level of the institution are discussed with the next level (Lee \& Dale, 1998; Tennant \& Roberts, 2001a; Nicholas, 2014; Witcher, 2014). Furthermore, King defines it as:

"A term that refers to the fact that communication up, down, and horizontally across the organization must sometimes go from person to person several times to be clearly understood." (King, 1989)

This element is closely related to the catchballing. This is because it shows that the goal (end) of every institutional level is to create the actions (means) needed to attain the intended goals and targets by the next-higher level (Nicholas, 2014).

Therefore, I think that catchball is the continual repetitive up, down, and horizontal essential communication for rational development of targets and the guidelines for achieving them. 


\section{Objectives Linked to Daily Work}

As the Hoshin objectives are cascaded down in the institution, the lower level managers meet them through the day by day plans, control, and management (Nicholas, 2014).

Consequently, Hronec (1993) illustrated Hoshin Kanri planning process as a model of seven fundamental elements:-

1. Strategy - It involves creation and communication reinforced by placing the appropriate mechanisms in place, training, and the existence of benchmarking for doing the right things from the first time, and all the time in the right way.

2. Goals.

3. Critical processes.

4. $\quad$ Output measures.

5. Essential activities.

6. Process measures.

7. Implementation.

\section{Different Descriptions of Hoshin Kanri Process}

In literature, there are different descriptions of Hoshin Kanri process. Although process descriptions varies not only on the level of details, but on the level of the big picture. Thus, these processes have the same principle. They start with the mission, vision, and/or long term plan. Therefore, through target alignment process, they finish up with the daily management. The basic foundation of strategic planning, common factor of Hoshin management, and BSC is their vision, objectives, strategies, and performance as shown in Figure 9. In the strategic planning process, action plans are developed in relation to the vision and objectives. The balanced scorecard (BSC) evaluates the performance in four perspectives. In addition, it is used to analyze the tasks with Key Performants Indicator (KPI). Hoshin is based on continuous improvement and process oriented. When there is a demand of improvement in the targets evaluated by BSC within four dimensions, Hoshin management intervenes (Yang \& Yeh, 2009, 996). 


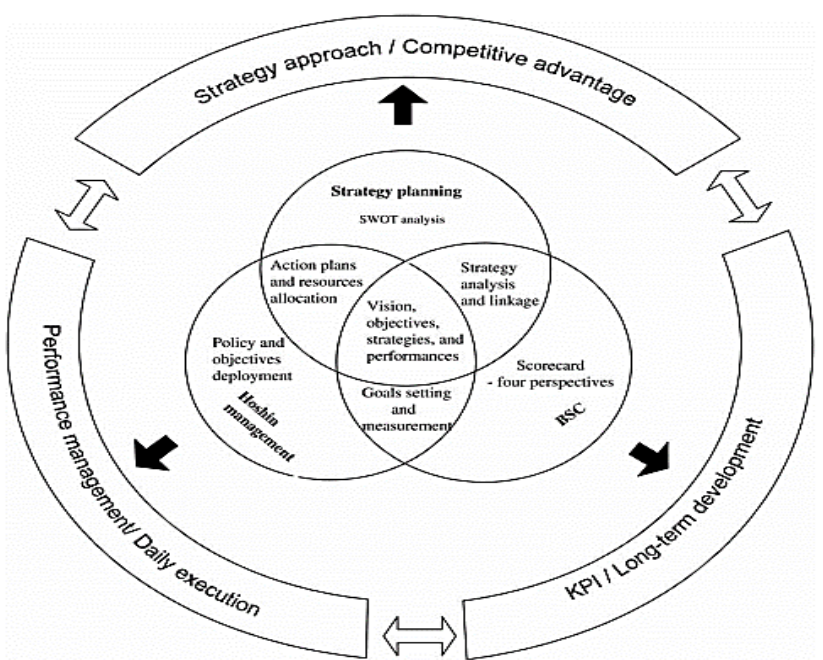

Figure 9. Strategic planning, BSC, and Hoshin management

(Source: Yang \& Yeh, 2009, 996)

\section{The Four Phases of Hoshin Kanri Planning}

As opined by Witcher \& Butterworth (1999), Hoshin Kanri is based on a FAIR (Focus, Arrangement, Integration, Remark) cycle. Hoshin Kanri Planning cycle has four phases which are similar, but are not equal to the $\mathrm{P}(\mathrm{lan}), \mathrm{D}(\mathrm{o}), \mathrm{C}(\mathrm{heck})$, and $\mathrm{A}(\mathrm{ct})$ phase in the PDCA methodology. The cycle starts with the phase of prevention (Focus) in which the previous management performance (Strategy) is profoundly reviewed. At this phase, the former year's performance is accurately investigated and focuses on the next year. Then, strategy (goals and priorities) is developed. In the following planning (Arrangement) phase, strategic priorities are organized to be consistent with units' priorities. Application (Integration) phase is a phase which is concerned with the integration of priorities with day-to-day activities and project works. Control (Review) phase consists of suitable management of day-to-day activities which is consistent with the strategic goals and supervision. The outcomes which are gained from this supervision and review phase give feedback to the focus phase (Asan \& Tanyaş, 2007: 1002)

\section{The First Phases: The Outlining/Prevention (Focus) Phase}

In the outlining/prevention (Focus) phase, the organizational situation is identified. The outlining phase is similar to the traditional design school planning model (Andrews, 1987; Mintzberg, 2000:35). Here, the method contains traditional environmental analysis with the application of tools such as Porters Five forces and PESTEL in addition to the internal analysis of resources and capabilities. 


\section{The Second Phases: The Objective/Planning (Arrangement) Phase}

In the objective/planning (Arrangement) phase, long and short term plans is developed in a top-down manner (Akao, 1991; Babich, 2005; Hutchins 2008). The Japanese version of Hoshin Kanri differs from the "Western version", whereas the "Western version" pays more attention to the analysis and the development of objectives (Jolayemi, 2008). Although the tools used are overlapping with traditional design school planning, the results are significantly different in the Hoshin Kanri approach. This is because the aim is not in developing an encompassing strategic plan. On the contrary, the aim is to keep objectives comprehensive and delimited. For comprehensive as the general objectives (vision), it is better to be somewhat general and in stating the general direction. Delimited, as the means to accomplish the general objective, will be limited not to many strategic objectives. Therefore, the ability to adhere not to too many issues is considered to be vital for the success of a Hoshin Kanri process.

\section{The Third Phases: The Operational /Application (Integration) Phase}

In the third operational /Application (Integration) phase, the essential words in all three alternative step-models above are deployment (policy deployment) and catch balling. Here, in this phase, the Hohsin Kanri methodology diverges more from traditional methodologies. The design school planning strategy work focuses only on how to implement the plans developed by the strategists. As Mintzberg, (2000, p.60) describes it, "in the planning model, implementation should be close-ended and converging and not permitting disturbances." Deployment and catchballing in the Hoshin Kanri approach are concepts that when they are defined, they encompass terms such as alignment, dialogue, and consensus (Akao, 1991; Tennant \& Roberts, 2001a). Deployment and catchballing also implies a management approach that has responsive, creative, and flexible principles. Practically, this approach is interpreted into a decentralized strategy work. Rather than developing the final and detailed plan at the top of the institution, strategy work which is consistent with the Hoshin Kanri approach includes the setting of vision, long term plans at the top, and objectives that are interpreted through conducting conversation within the institution and with all levels of employees. However, these employees are invited to work on their substrategy on how to achieve the general objectives. Jolayemi defines catchball as "relative up, down, horizontal discussions, and joint analysis necessary for effective determination of objectives, strategies, and means." (Jolayemi, 2008:310)

\section{The Fourth Phases: The Control (Review) Phase}

In the fourth phase, the Control (Review) phase, more important characteristics of the Hoshin Kanri approach surface. One of these 
characteristics is the need for continuous process development which indicates that the Hoshin Kanri process takes a number of cycles to start. Also, it will never be completely developed. In addition, the second characteristic is the relationship between participation in strategy work and the obligation for accomplishing the agreed actions. It is concluded that the difference between the traditional design school model and the Hoshin Kanri approach is that the traditional design school model often ignore the balancing of authority and responsibility. "Why should co-workers assume responsibility to carry out actions when they have no authority to define actions?"

(Mintzbeg, 2000). On the other hand, the Hoshin approach is "about using a participative and shared commonality of direction, rather than top-down command and control. The over-arching principle is that everybody should be involved in strategy (work)" (Witcher, 2014:88).

I think that the familiarization phase is very critical and important. It is about getting employees to know each other and set-up a level of trust and confidence and to identify the strategic issues that are most interesting to the management of the institution. When top management practices the PDCA thinking it will be compelled to create more common assumptions about the institution. However, these assumptions will be progressively transformed from general statements to common convictions among employees and managers. After some time, the assumption will be translated into long-term objectives and a vision.

As mentioned before, the PDCA thinking and a "Management by Objectives” approach are fundamental prerequisites in Hoshin Kanri process. On the "tool-level”, researchers propose some methods that are derived from the total quality management tradition. Hutchins (2008) explains ideas and tools pertaining to six sigma, quality circles, the kano model, pareto diagrams, fish-bone diagrams lean manufacturing, etc. Furthermore, Babich (2005) concentrates on the administrative process and the PDCA, thinking and presenting the templates of how to administer the strategy work process. In addition, the A3 methodology is considered as a common tool to operationalize the PDCA logic (Tennant \& Roberts, 2001a).

\section{What is the Difference between Hoshin Kanri Strategic Planning Process and Any Other Strategic Planning Process? The Core Hoshin Planning Process}

Although the model of Hoshin planning process may look similar to any other planning process, yet the distinctness is clear in the application of planning tools that is consistent with quality principles and tools. These tools include PDCA, a few number of critical points for creating yearly objectives 
(the Pareto principle), the customer focus, fact-based data, and root-cause problem solving. Therefore, the final step in the process focuses on reviewing the Hoshin process itself - this concentration with process is unfamiliar in conventional strategic planning. The one year plan is the beginning of the heart of Hoshin planning process. Yearly, few key objectives that are derived out of vision and long- term plans must be accomplished during the year (step 3). Then, the fundamental departments/functions are engaged in creating sub-objectives and plans. A process of reaching agreements about how plans can be achieved through managed coordination during deployment is drawn. Since this has to do with throwing possibilities to and fro between effected parties, it is equated with a game of catchball (in step 4, figure 10) (Witcher, 2014).

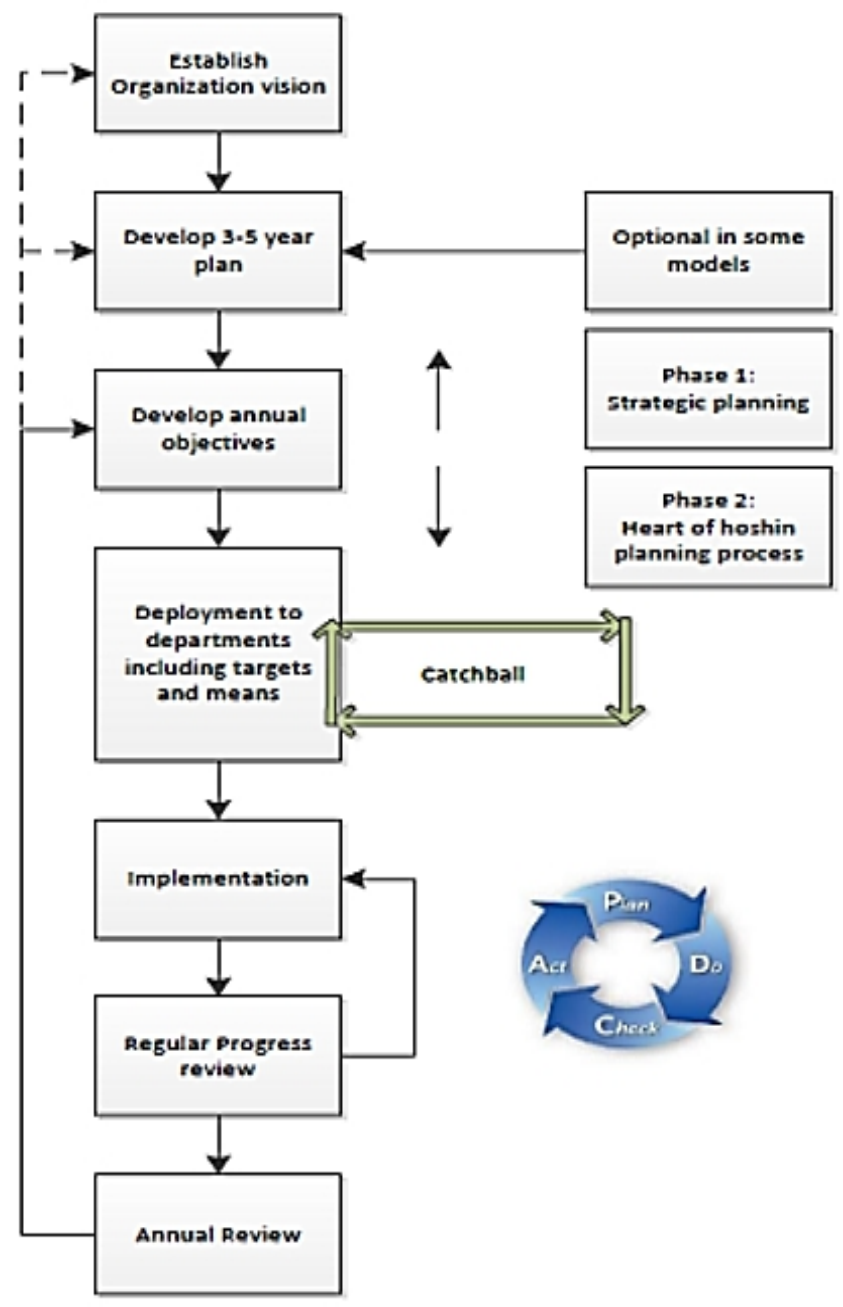

Figure 10. The core Hoshin planning process

(Source: Jolayemi, 2008) 


\section{The Steps of Hoshin Planning Process}

Boisvert (2012) indicated the first steps of Hoshin planning like any strategic planning process. It starts with gathering data and information on current performance of the institution, its current and future customers, and their needs and expectations. The mission and vision are reviewed, and it develops the institutional measures of success. Then, Hoshin strategic planning process departs from standard planning through four important ways (Boisvert, 2012): -

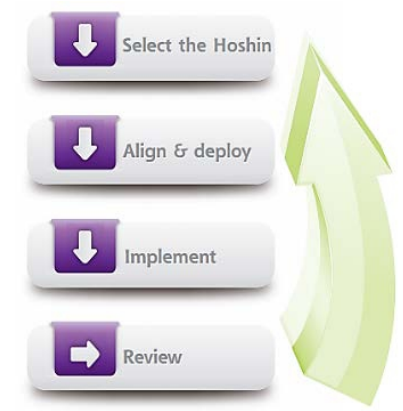

Figure 11. Hoshin Planning Macro-Level Process

(Source: Boisvert, 2012)

\section{First Way: Focus - Selecting 'One’ Hoshin}

The success of the strategic plan can be increased by defining the priorities at the executive level. Defining the priorities can be a hard task for the leaders. Subsequently, executives can manage this hard task by arranging the Hoshins that are not chosen for a certain year in a Gantt chart. Also, they assure their employees that a Hoshin which is not chosen in a certain year may be the one selected next year or the year after. What distinguishes a 'Hoshin'? A Hoshin is an advanced objective with three features. First, a fundamental change in the systems of the institution becomes a must. Second, it necessitates the involvement of the whole institution to attain. Third, if achieved, it will lift the institution up to its higher level of performance. However, accomplishing a Hoshin is transformational to an institution.

\section{Second Way: Organizational Involvement - Conducting 'Catchball'}

The catchball process is essential for successful implementation of Hoshin Kanri, since it constructs the bridge between choosing the Hoshin and implementing it. Catchball is derived from a children's ball game, but in place of a ball, an idea is thrown from one person to another. Catchball is an essential process that necessitates continuous communication to develop the applicable targets and means, and their deployment at all levels and sections in the institution. In addition, feedback in multi-directional horizons must be given through managed processes (Tennant \& Roberts, 2001). 
The product of the catchball process is the plan itself which comprises of a connected set of planning tables. In catchball, managers and senior employees develop the strategies, tasks, and metrics that sustain the accomplishment of the Hoshin. The Affinity Diagram is one of the essential Hoshin planning tools that are used to build an annual plan. This is carried out by allowing people to answer questions within a very short period of time. For the unprecedented strategies, people in charge search for a realistic assessment of what it will take to carry out these strategies. After then, the comprehensive plans are brought back up through the higher levels of the plan, in order to allow for modification in the highest-level strategies. In this context, the word 'catchball' refers to tossing back up these plans (Boisvert, 2012).

\section{Third Way: Using the Planning Tools and Tables}

The products of the group's work at a meeting become the components of the plan itself. There is a saying, 'People support what they help create.” Tools like the ID invite a high degree of interaction and are designed to support consensus decisions. Executives who work with their colleagues to produce a shared picture of drivers and outcomes like this, more often than not, invest well in supporting the outcome later. Hoshin planning gives great attention to the documentation of the planning process and the plan itself. The group processing tools and planning tables are used in the planning meetings instead of traditional meeting (Boisvert, 2012).

\section{Fourth Way: Reviewing the Plans}

One of the less exciting, but strongest features of the Hoshin planning process is the review.

More than the typical progress report presentation, Hoshin planning strategy owners must report regularly on whether metrics were made or missed. If missed, what is the root cause that led to the result? The expectation is that plan leaders will present data and what their plans are for correction as part of the review. Care is taken to ensure that review meetings will be conducted weekly, monthly, and quarterly as learning opportunities from 'Mistakes', reaffirms on what is important to the institution, and the removal of the completed parts of the plan (Boisvert, 2012).

Hoshin is mainly paying great attention to sustainability and building strengths for increased competitiveness. While Hoshin concentrates on results, it does so by unceasingly refining the processes involved in order to avoid repeatability of performance and in achieving consistency. Hoshin presents discipline, communicates the same goal at all levels, and ensures the achievement of goal agreement or real alignment. In contrasting management by objective (MBO), which focuses attentions on individual performance and 
follows an inflexible hierarchical ranked line of authority and responsibility, Hoshin follows a process flow chart and evaluates team performance. Unlike MBO, Hoshin does not focus on "one leap at a time" kind of approach. Subsequently, the effect is to concentrate on continuous improvement to improve process capability, to avoid mistakes, to capture best practices and ideas, and to achieve quality (Zairi \& Alan, 2014).

Hill (1994) says that Hoshin Kanri:-

1. helps make unification within an institution and supports a consensus of the institution objectives at all levels;

2. concentrates on a vision of the future of the institution;

3. harmonizes the efforts of all people within an institution into actions that move the whole institution towards its objectives;

4. develops and creates process to carry out improvement year after year;

5. makes engagement and commitment to both the direction and application ways chosen;

6. enhances interdepartmental collaboration;

7. employs and strengthens the PDCA cycle in every month progress reviews;

8. develops a planning and implementation system that is reactive, adaptable, yet disciplined and systematic;

9. provides a mechanism for leadership to understand the strategic problem areas in an institution, and enable prioritization;

10. creates faster and more precise feedback circles; and by use of the catchball process, it provides the best communication between both levels and departments concerned.

Factors which are Likely to Enable or Hinder the Implementation of Hoshin Kanri Planning in Educational Institutions

There are many factors that may enable or hinder the implementation of Hoshin Kanri planning in educational institutions. However, these factors can be summarized as follow:-

\section{Written Strategies and Strategic Work}

Hoshin strives at planning and implementing strategic objectives. Also, they have a long term focus. In addition, the use of written strategies has an effect on the implantation of Hoshin Kanri. The written strategies are usually used as a tool for communicating the long term plans in the institution.

\section{Lean Experience and Work with Continuous Improvement}

Hoshin strive in cascading strategies and long term plans into the institution. Continuous improvement is an approach for change. Hoshin 
continuous improvement takes into account the application of the PDCA methodologies, experience of daily management, and a general continuous improvements mindset (Kesterson, 2014).

\section{Strategic or Operational Focus}

The focus of the institution impacts the implementation of Hoshin Kanri. This is because the benefits of adopting Hoshin Kanri take up to four years to attain according to Hoshin experts (Kesterson, 2014). Hence, it is more a way of living than the implementation of a methodology. Considering this, institutions implementing Hoshin Kanri should have a long term strategic focus. However, the institution needs to achieve small quick wins to involve the employees and make them concerned. The small quick wins are operational issues.

\section{Leadership Commitment}

Leadership commitment and involvement impacts the implementation of Hoshin Kanri since the leader puts the directions for the institution. Without commitment and involvement from both the leadership and top management, the importance of the implementation of Hoshin Kanri will be in doubt.

\section{Top Management Team and Regular Top Management Team Meetings}

Top management team and regular top management team meetings impact the implementation of Hoshin Kanri because Hoshin Kanri is comprehensive besides a systematic process. Teamwork, engagement and involvement, are essential pillars in Hoshin Kanri. Taking into account this, the people in the top management team should understand how to work together before the implementation of Hoshin Kanri. Hoshin is also a systematic process for achieving strategic objectives. In case that the top managers are not accustomed to work together and do not have frequent top management team meetings, this can hinder the implementation of Hoshin Kanri (Tennant \& Roberts, 2001a).

\section{Institution Open for Change and Institutional Culture}

It is important to understand the institutional culture and its acceptance for change before implementing Hoshin Kanri. However, Hoshin Kanri deals with change on how the institution plans and implements its strategy. As mentioned before, Hoshin requires everyone to be involved. In addition, the employees will achieve the strategic objectives and they will be impacted by the end result (Tennant \& Roberts, 2001; Kesterson, 2014). 


\section{A Structured Process for Strategic Planning using Hoshin Kanri Methodology in Educational Institutions}

A structured process for implementing Hoshin Kanri planning was developed from the Hoshin Kanri literature. This literature was integrated with the knowledge attained by the researcher through a face to face workshop that is divided into interactive sessions. However, it was conducted under close guidance by the research with 45 persons. These persons were responsible for the strategic planning of some of the Egyptian public and private universities. This was held during the lectures that the researcher conducted as a part of teaching practices for "Strategic Planning in Educational Institutions" course. However, this course is one of the courses in Professional Diploma in Quality and Accreditation Management Systems in Educational Institutions at Ain Shams University. From this workshop, a structured process was developed in two phases that cover the Plan part of the PDCA methodology. In phase one, "the scanning" which aims at understanding the history of the institution, is giving a description and is characterizing the present strategies and strategists in the institution. The scanning phase is followed by the second phase, "formulation phase" in which three strategies are identified. Therefore, these three strategies are as follows (Melander et al., 2015; Jackson, 2006): -

(1) Apply a traditional strategic planning process, which comprises of workshops, mapping the internal and external environment, developing a vision, and a long and short term strategic objectives. In addition, this is to be followed by a deployment process.

(2) Apply an experienced based strategy, in which the PDCA methodology is the dominant tool repetitively used for resolving issues. Gradual deployment of the technique occurs in the institution when the top management is supportive.

(3) A combination of the two methods in which the second strategy gradually resulted in the adaption of more traditional planning tools for establishing corporate objectives and vision.

\section{The 10 Steps of the Application of Hoshin Kanri Planning in Educational Institutions}

Akao proposed 10 Steps for applying Hoshin Kanri as outlined below (Akao, 1991):-

1. Providing a context for and focusing institutional action (Establishing annual policy)

Steps 1 to 3 are similar to the institutional planning process. Also, it relates to the determination of longer-term policies which develops the context from which the institution's annual policy can be derived. 
Step 1: Establish an institution motto, quality policy, and promotion plan.

Step 2: Devise long and medium term management strategies.

Step 3: Collect and analyze the information.

The institution vision which is not mentioned within the steps is a general guideline. However, it will not be changed repeatedly. Also, the management concept or motto is a yearly statement. Quality policy concentrates on customer satisfaction which is defined in terms of Quality, Cost, Delivery and Employee (QCDE). Long and medium term policies are developed within the context of the institutional vision. Step 3 is concerned with information that shows the current position of the institution. This step also provides the essential knowledge for determining annual policy. Thus, the annual Hoshin Kanri process is derived in this step through the application of the PDCA cycle. To all intents and purposes, the freedom of institutions to carry out Steps 1 and 2 will be deeply influenced by the context within which they function.

\section{Aligning institutional action (Deploying annual policy)}

Steps 4 to 7 apply the annual policy to manage institutional activities. This is done through the translation of targets and means which bring about policies for every part of the institution.

Step 4: Plan the target and means.

Step 5: Set control items and prepare a control item list.

Step 6: Deploy the target and means.

Step 7: Deploy the control items.

Targets are expected results, while means outline the actions taken to achieve targets. The application of quality control (QC) is essential in the formation of targets and means. Consequently, quality control (QC) apply the Paretio analysis to make sure that data based priorities become the central point for action. Managers employ annual policy to determine targets and means which are suitable to them. After then, they are passed down to the institution. Higher level means to become the focus for next level managers to decide their targets and means. However, this process needs repetitive coordination between different institutional levels. In Hoshin Kanri, control items are the measures that monitor the progress of achieving targets. These measures result from the application of the PDCA cycle during the development of policy and related plans. In addition, they are linked to the target and means, and are developed by the individuals responsible for the target/mean setting process. After setting the targets and the means and control items, the next two steps involve their deployment all through the institution. 


\section{Integrating institutional action through implementation (Implementing annual policy)}

The implementation of the policy plan is governed by the culture and purpose of the institution. There is an implied assumption that as soon as the process has reached the implementation stage, success will be tagged alongside with it.

Step 8: Implement the policy plan.

\section{Reviewing the results of institutional action (Reviewing annual policy)}

Step 9. Check the results of the implementation.

Step 10: Prepare the status report for implementing Hoshin Kanri.

Steps 9 and 10 involve the review of the development of policy deployment which entails two forms. The first form involves examining the results of the implementation through the application of the PDCA cycle continuously at every institutional level. This will decide suitable data analysis based corrective action where anticipated results are not being fulfilled. Critical to this is the process which produced the results. However, it is the focus of any corrective action, not just the results itself.

The process is repetitive and it serves as feedback into Step 3. Review step aims at allowing changes to be made to the courses of action or policy. The second form of review involves the development of Hoshin Kanri, where an institution pursues a continuous improvement of the process. Step 10 involves composing a report that describes in details the status of progress towards the achievement of targets at each level of the institution. Essentially, this is reporting on the PDCA of the yearly policy. Also, it creates a foundation upon which decisions will be made for future policy.

Furthermore, this classification provides a conceptual model of Hoshin Kanri as seen in figure 13 below. As mentioned earlier, the essential requirement for Hoshin Kanri is a successful TQM. Planning, doing, monitoring, and the stage at which corrective actions is taken are regarded as the four stages of Hoshin Kanri. 


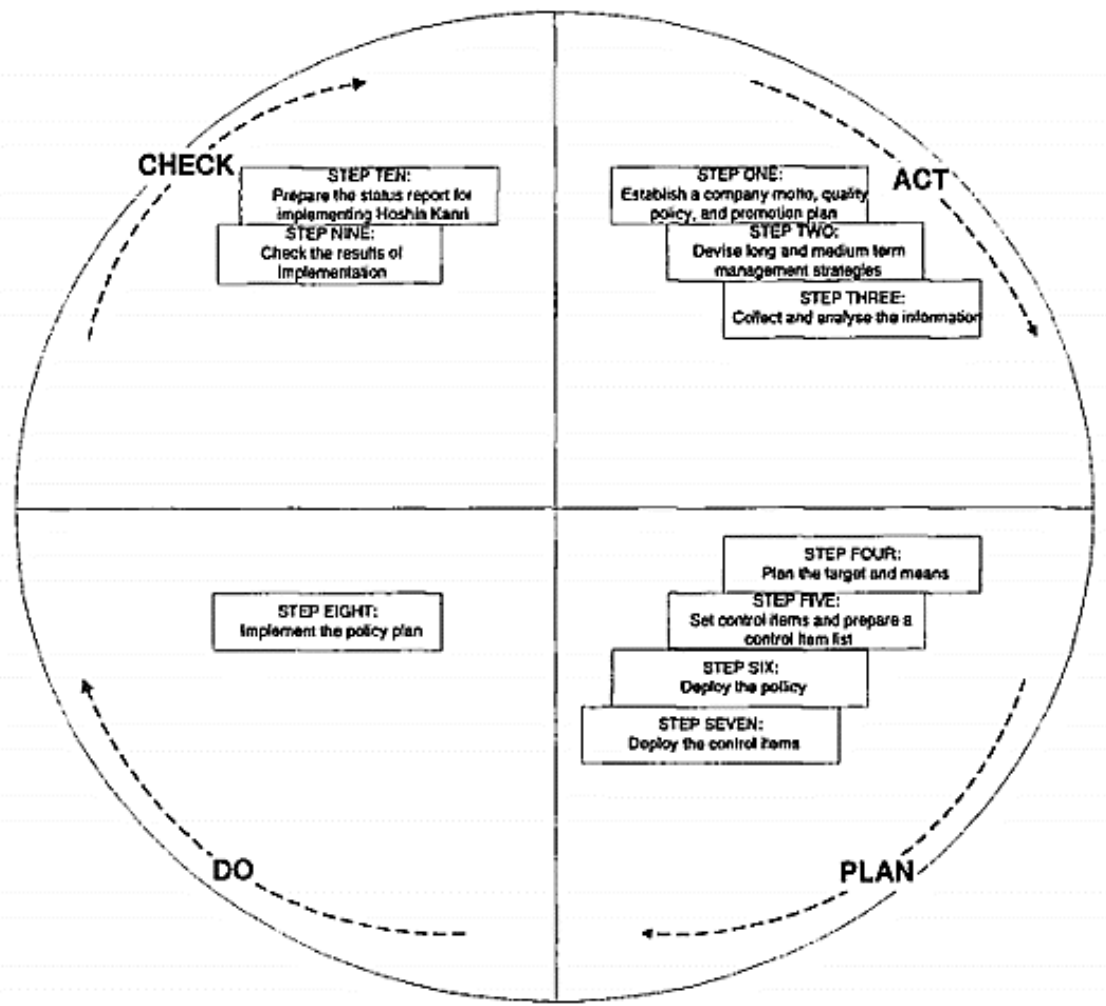

Figure 13. PDCA \& Akao's 10 Steps of Hoshin Kanri

(Source: Butterworth, 2002)

Hoshin Kanri - from Strategy to Action!

\begin{tabular}{|c|c|c|c|c|c|c|c|c|c|}
\hline \multirow{2}{*}{$\begin{array}{c}\text { Vision } \\
\text { In the } \\
\text { next } 7 \\
\text { years will } \\
\text { be: } \\
\text { A) ranked as } \\
\text { top } 10 \\
\text { global } \\
\text { supplier } \\
\text { B) enjoy } 50 \% \\
\text { or more of } \\
\text { income } \\
\text { from exports }\end{array}$} & $\begin{array}{l}\text { Overall } \\
\text { Business } \\
\text { Strategic } \\
\text { Plan } \\
\text { Scope } \\
\text { Dispersion } \\
\text { Size of } \\
\text { market } \\
\text { Financial } \\
\text { plan }\end{array}$ & $\left.\begin{array}{l}\text { Drivers } \\
\text { Customers } \\
\text { Employees } \\
\text { Suppliers } \\
\text { Processes } \\
\text { Organisation } \\
\text { Technology } \\
\text { Finance } \\
\text { Design! } \\
\text { Innovation }\end{array}\right\}$ & 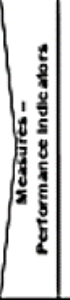 & 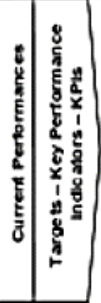 & \multirow{2}{*}{ 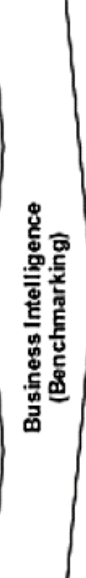 } & $\begin{array}{l}\text { Revised } \\
\text { Targets } \\
\text { from } \\
\text { Bench } \\
\text { marking } \\
\text { and } \\
\text { Cost of } \\
\text { Poor } \\
\text { Quality } \\
\text { analysis }\end{array}$ & \multirow{2}{*}{ 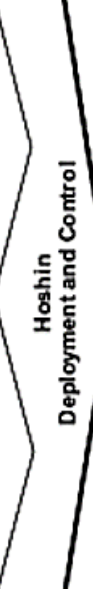 } & $\begin{array}{l}\text { TQM } \\
\text { Volce of the } \\
\text { Customer } \\
\text { supply Chain } \\
\text { Mansaement } \\
\text { six sigma } \\
\text { Lean Manu- } \\
\text { tacturing }\end{array}$ & \multirow{2}{*}{ 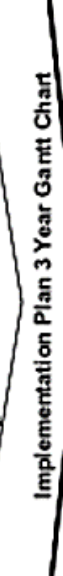 } \\
\hline & $\begin{array}{l}\text { Sub- } \\
\text { Strategies } \\
\text { (for each } \\
\text { Product or } \\
\text { Service) }\end{array}$ & $\begin{array}{l}\text { Threats } \\
\text { Legislation } \\
\text { Product-Liabity } \\
\text { WTO } \\
\text { GEO politics } \\
\text { Tariffs } \\
\text { Competition } \\
\text { Customer } \\
\text { and so on }\end{array}$ & $\begin{array}{r}\text { Mea } \\
\text { of Th } \\
\text { Prob } \\
\text { Sev } \\
\text { Oppo } \\
\text { Dete }\end{array}$ & $\begin{array}{l}\text { pability } \\
\text { verity } \\
\text { ortunity } \\
\text { ection }\end{array}$ & & $\begin{array}{l}\text { Counter- } \\
\text { measures } \\
\text { Use } \\
\text { SWOT } \\
\text { Loose } \\
\text { Brick } \\
\text { and so on }\end{array}$ & & $\begin{array}{l}\text { engineering } \\
\text { improvement } \\
\text { Projects } \\
\text { ouality Circiees } \\
\text { Ouality } \\
\text { 8ystems } \\
\text { ofd } \\
\text { Education }\end{array}$ & \\
\hline & in $K_{t}$ & . & & & & & & Total Quality & \\
\hline
\end{tabular}

Figure 12. Hoshin Kanri process and total quality management

(Source: Hutchins, 2008) 
PDCA- cycle

PDCA- cycle consists of four phases and eight steps as it is presented in 1 (Du et al., 2008).

\begin{tabular}{|c|c|c|}
\hline Phase & Step & Content \\
\hline \multirow[t]{4}{*}{ plan } & 1 & $\begin{array}{c}\text { Analyses the existing conditions and finds out the current and prevailing } \\
\text { problems. }\end{array}$ \\
\hline & 2 & Determines the root causes of those problems. \\
\hline & 3 & Identifies the principal factors from root causes. \\
\hline & 4 & $\begin{array}{l}\text { Applies the solutions and improvement plan according to the principal } \\
\text { factors. }\end{array}$ \\
\hline Do & 5 & Performs the plan and measures. \\
\hline Check & 6 & Checks the implements according to the requirements of the plan. \\
\hline \multirow[t]{2}{*}{ Action } & 7 & Sums up experiences and reinforces achievements. \\
\hline & 8 & $\begin{array}{l}\text { Turns problems that have not been solved or that appears newly in the } \\
\text { next cycle. }\end{array}$ \\
\hline
\end{tabular}

PDCA- cycle is the heart of the Hoshin Kanri and continuous improvement. When Hoshin Kanri is completely implemented, the PDCAcycle has an effect on every function daily. Senior management uses the cycle in determining the direction, follow-up, and improvement of the whole institution. Middle management is coordinating departmental actions and targets to assist the upper level cycle. When going down in the institution, the turning speed of the PDCA-cycle is increasing. The annual cycle starts with act. Here, the top level management presents the next year few vital objectives to the next level of the institution. Figure 14 indicates the relationships between annual Hoshin and the PDCA- cycle (Leppänen, 2014).

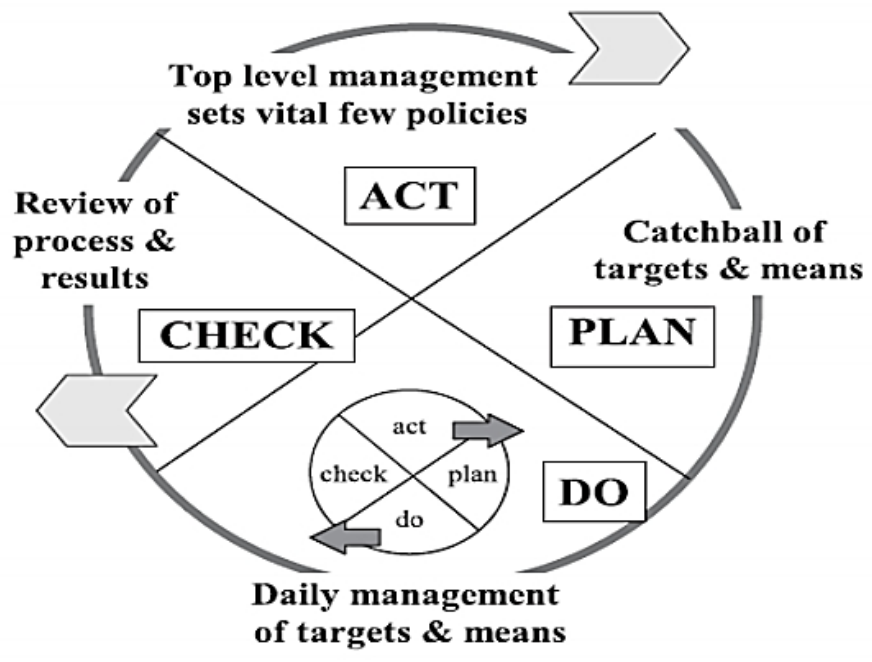

Figure 13. Annual Hoshin and PDCA- cycle

(Source: Witcher, 2002). 
In the next phase plan, "catchball” process is taking place. This process is concerned with setting the practical targets based on vital few objectives for the next year by all departments. Also, it ensures that the targets and means are not mismatching. The catch-ball comes to an end after the opinions of so many people right down to the front line have been brought together and after information have been fed to the top management. The nested PDCA cycles are the result out of the catch-ball process where all participants know well their roles to reach the annual targets. In the phase do, the targets and means are deployed to the daily management where continuous processes are controlled as part of daily operations. In check phase, the results out of the processes are continuously checked and corrective actions are taken when needed (Kondo, 1998).

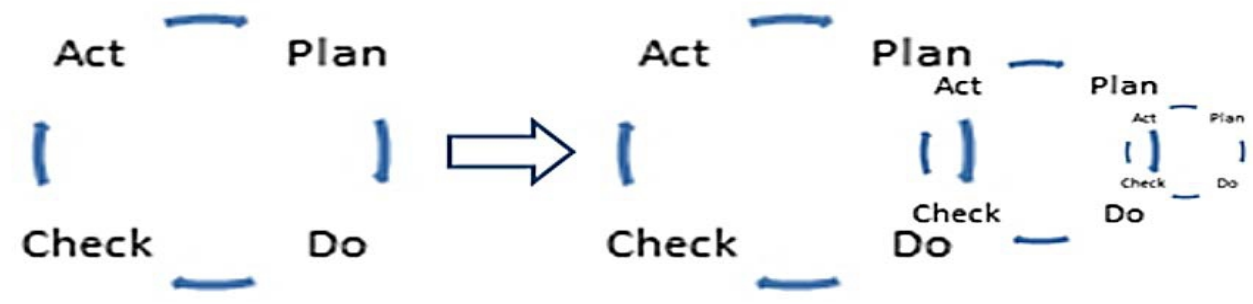

Figure 14. Nested PDCA cycles

(Source: Jackson, 2006).

\section{Conclusion}

Hoshin Kanri planning is a systematical methodology for achieving strategic institutional improvements through focusing on choosing the institutional priorities, participation of all employees, the use of wellregulated and established planning and improvement tools, and the application of a structured review process that leads to a continuous improvement.

Hoshin Kanri is a methodology for perfecting strategy execution. This is done through applying PDCA to the planning process and the application of a few significant strategic objectives of an institution. Hoshin Kanri is best used by institutions that adopt TQM. Hoshin Kanri is also a structured framework for strategic management. However, it has four essential tasks. Firstly, it focuses on the attention of an organization on a business direction by setting a few vital strategic priorities every year. Secondly, it aligns these few strategic priorities with business plans and programs. Thirdly, it integrates them with every day management. Finally, it provides a well-defined methodical review of their progress.

The most significant Key defining features of Hoshin Kanri are PDCA which is considered to be a basis for improvement. It also provides a common approach to problem solving and the setting of priorities. In 
addition, catchball is another significant defining feature of Hoshin Kanri. Catchball is linked to the broader concept of nemawashi which is a distinctive feature of institution life. Furthermore, it is a process of achieving consensus that aims at determining the correct course of action for a specific policy.

\section{Future Research}

There is a need in the future to address both strategy work (with the Hoshin Kanri planning methodology) in addition to institutional structure in which development and deployment processes can be established. Practical examples of Hoshin Kanri planning methodology within the education sector in Egypt and Arab world need to be explored. Also, there is the need to further explore the factors which affects the implementation and development of the process.

\section{References}

Akao (1991). Hoshin Kanri: Policy Deployment for Successful TQM, Productivity Press, Cambridge, MA.

American Supplier Institute (1989). Policy Management - Executive Briefing Manual, American Supplier Institute, Michigan.

Andrews (1987). The Concept of Corporate Strategy, Irwin, Homewood, Ill. Ansoff (1968). Institution Strategy, London, Penguin Books.

Asan \& Tanyaş (2007). Integrating Hoshin Kanri and the Balanced Scorecard for Strategic Management: The Case of Higher Education, Total Quality Management \& Business Excellence, 18(9), 999-1014.

Babich (1996). Hoshin Handbook (2nd Ed.), USA, Total Quality Engineering, Inc.

Babisch (2005). Hoshin Handbook. Total Quality Engineering. Poway, US. Boisvert (2012). Strategic Planning Using Hoshin Kanri, Retrieved on June 27, 2014 , Available at: URL:

https://www.goalqpc.com/cms/docs/whitepapers/GOALQPCHoshinWhitepa per.pdf

Butterworth \& Rosemary (2001). Hoshnn Kanri: An Exploratory Study Nissan Yamato Engineering Ltd. Ph.D. dissertation, University of Durham.

Cole (1998). Learning from the quality movement: what did and didn't happen and why? California Management Review, 41, 43-73.

Colletti (1995). A Field Guide to Focused Planning: Hoshin Kanri American Style, The Wood ledge Group, East Granby, CT, USA.

Davidson (1995). The Transformation of Management, London, Macmillan Business Press.

Drucker (1954). The Practice of Management. New York. 
GOAL/QPC (1989). Hoshin Planning: A Planning System for Implementing Total Quality Management (TQM), research report 89-10- 03, Methuen MA: GOAL/QPC. 52 pps.

$\mathrm{Du}$ et al. (2008). Application of the PDCA-cycle to Performance Management system. Shangdong University of Technology. Shangdong. Hronec (1993). Vital Signs Using Quality, Time and Cost Performance Measurements to Chart Your Institution's Future, AMACOM, New York. Hutchins (2008). Hoshin Kanri: the strategic approach to continuous improvement, Gower Publishing, Farnham, UK. Integrated Quality Dynamics (1997). TQM: Hoshin, Retrieved on June 27, 2014 , Available at: URL: http://www.iqd.com:80/hoshin.htm Jackson (2006). Hoshin Kanri for the lean enterprise, CRC Press, Boca Raton.

Jolayemi (2008). Hoshin kanri and hoshin process: A review and literature survey, Total Quality Management, 19 (3), pp. 295-320.

Kesterson (2014). The basics of Hoshin Kanri, CRC Press, Boca Raton.

King (1989). Hoshin Planning: The Development Approach, GOAL/QPC, Methuen, MA, USA.

Kondo (1998). Hoshin kanri-a participative way of quality management in Japan, The TQM Magazine, 10(6), pp. 425-431.

Lee \& Dale (1998). Policy deployment: an examination of the theory, International Journal of Quality \& Reliability Management, 15(5), 520-540.

Leonard \& McAdam (2002). The corporate strategic-operational divide and TQM, Measuring Business Excellence, 6(1), pp. 5-14.

Leppänen \& Kalle-Pekka (2014). Study of the hoshin kanri strategy deployment elements in Sappi Kirkniemi Paper Mill, Master's thesis, Tampere University of Applied Sciences.

Marksberry (2011). The theory behind hoshin: a quantitative investigation of Toyota's strategic planning process, International Journal of Business Innovation and Research, 5(3), pp. 347-370.

Melander et al. (2015). Initiating the Hoshin Kanri approach in small and medium sized companies, a paper submitted at the $22^{\text {nd }}$ EurOMA Conference, June 26th to July 1st, 2015, Retrieved on June 27, 2014 , Available at: URL: http://urn.kb.se/resolve?urn=urn:nbn:se:hj:diva-28692

Mintzberg (2000). The Rise and Fall of Strategic Planning, Prentice Hall. London, UK.

Nicholas (2014). Hoshin kanri and critical success factors in quality management and lean production, Total Quality Management \& Business Excellence, DOI: 10.1080/14783363.2014.976938.

Rank Xerox (1992). The European Quality Award Rank Xerox, Submission Document, Marlow: Rank Xerox. 
Shiba \& Shoji (1993). A New American TQM: Four Practical Revolutions in Management. Productivity Press, Cambridge MA.

Skinner (1969). Manufacturing - missing link in institution strategy. Harvard Business Review, Boston.

Sobek \& Smalley (2008). Understanding A3 thinking, Productivity Press, Boca Raton, FL.

Tennant \& Roberts (2000). Hoshin Kanri: A Technique for strategic quality management, Quality Assurance, 8, 77-80.

Tennant \& Roberts (2001a). Hoshin Kanri: a tool for strategic policy deployment, Knowledge and Process Management, 8(4) pp. 262-269.

Tennant \& Roberts (2001b). Hoshin Kanri: Implementing the Catchball Process, Long Range Planning, 34, 287-308.

Total Quality Engineering (1997). “Hoshin planning”, Retrieved on June 27, 2014 , Available at: URL: http://www.tqe.com:80/tqehelp/hoshin.html

Watson (1991). Understanding Hoshin Kanri, in Akao, Y. (Ed.), Hoshin Kanri: Policy Deployment for Successful TQM, Productivity Press, Cambridge, MA.

Watson (2005). Design and Execution of a Collaborative Business Strategy. Journal For Quality \& Participation, 28, (4), 4-9.

Witcher \& Butterworth (1997). Hoshin Kanri: a preliminary overview. Total Quality Management, 8, (2-3), 319-323.

Witcher \& Butterworth (1999). Hoshin Kanri, How Xerox Manages, Long Range Planning, June 32(3), 323 - 332

Witcher (2002). Hoshin kanri: A study of practice in UK, Managerial auditing journal

17 (7), 390-396.

Witcher \& Chau (2012). Strategic management and varieties of capitalism: managing performance in multinationals after the global financial crisis, British Journal of Management, 23 (March), S58-73.

Witcher (2014). Hoshin Kanri through the eyes of English Language Texts, The journal of business studies, 53, (3), 72-90.

Witcher (2014). Hoshin Kanri, Perspectives on Performance, 11(1), 16-24

Yang et al. (2009). An Integrated implementation model of strategic planning, BSC and Hoshin management, Total Quality Management \& Business Excellence, 20(9) 989-1002.

Zairi, Mohamed \& Erskine (2014). International Journal of Applied Strategic Management, 2 ( 2), Special Edition, Driving Strategy with Quality: A Useful Insight. Excellence is Born out of Effective Strategic Deployment: The Impact of Hoshin Planning, Retrieved on June 27, Available at: URL: http://www.managementjournals.com/journals/strategic/vol2/12-2-2-2.pdf 